\title{
Built Environment and Landscape Design as Tools for Climate Resilient Cities and Regions
}

\author{
By Anastasia Nikologianni, Peter J. Larkham ${ }^{ \pm} \&$ Kathryn Moore ${ }^{\ddagger}$
}

\begin{abstract}
This paper explores project frameworks and design methods in order to reveal innovative ways and processes for creating more resilient cities and regions. Considering major environmental, economic and social challenges and extracting key quality elements from pioneer development schemes, the aim is to identify methods and policies that have a significant impact on the transformation, landscape quality and sustainability of places at city and regional scale. Starting with the model of design quality in project delivery, and looking at a transformation model, the paper discusses best practices for the development of concept and implementation before it considers the model of pan-European collaboration. An investigation of climate adaptation issues through the 'Room for the River', a national programme in the Netherlands, demonstrates the significance of landscape design, low carbon and spatial quality as vital aspects of the built environment. The West Midlands National Park (WMNP UK), a major infrastructure proposal, demonstrates how a broader vision can help drive environmental, social and economic transformation in a region, whilst SATURN, an EIT Climate-KIC project, reveals the first stages of a pan-European city collaboration with the aim of reintegrating the natural assets within the climate change impact strategies of the participating cities, and exchanging knowledge between European regions. This paper suggests that landscape design and the built environment are important drivers towards a successful low carbon transition, and they can simultaneously enhance social and landscape identity and boost the economy of a region.
\end{abstract}

\section{Introduction}

This paper explores three large-scale models that have demonstrated ways in which principles leading to low carbon and resilient cities have been embedded. It is based on a broader piece of research that has examined several pioneer landscape-led projects across Europe, through the lenses of climate emergency and landscape quality. The models discussed here have demonstrated best practices and new methodologies in relation to strategic design and environmental resilience. They were selected to represent three key steps in the delivery of a sustainable infrastructure development; the establishment of a vision (design quality), the transformation of views and opinions (of the landscape legacy) and the importance of systemic change in cities and regions through open collaboration and exchange of knowledge.

\footnotetext{
*Post Doctoral Research Fellow, School of Architecture and Design, Birmingham City University, UK.

${ }^{ \pm}$School of Engineering and the Built Environment, Birmingham City University, UK.

${ }^{\ddagger}$ School of Architecture and Design, Birmingham City University, UK.
} 
The scale of climate change and its impact on our cities and regions is now widely recognizable, however it is only recently that it has been termed the 'climate emergency'. The 'resilient city' is a broad but often controversial term, since resilience can be interpreted in so many ways. In the larger spatial context, it is often challenging to identify the true environmental or most sustainable steps that will support carbon neutral communities.

Built environment or landscape design are not new concepts, however the concepts of a carbon neutral development, or sustainable cities, through innovative design are fast developing and becoming adopted. The use of multidisciplinary teams and collaborative projects with the aim to enhance resilience, re-imagine landscape identity and boost social and economic benefits seems to be a beneficial option to future-proof our cities. This paper agrees with Nijhuis and Jauslin, ${ }^{1}$ that contemporary societal challenges including rapid urbanisation, an ecological crisis and climate emergency demand fundamental review of the planning and design of our landscapes at urban and regional scales. It is important that built environment and landscape infrastructure are integrated in order to allow, as Nijhuis and Jauslin suggest, "design principles to gain operative force in territorial transformation processes." The review proposed by their research aligns with the focus of this paper, that is to demonstrate how innovative planning and design models can aim to address climate extremes, and propose new ways of creating low carbon cities reinforced by the introduction of policy and decision-making methods throughout their processes. Landscape infrastructure and urban developments are the vehicles to re-establish the role of design as a means of integrating environmental principles in strategic schemes. It is through the models examined in this paper that such established concepts are dealt with in novel ways, facilitating transformation and innovative ideas.

This research introduces three models that have dealt with environmental challenges from different angles. The model used in the Room for the River project, (the Netherlands) demonstrates how design quality is integrated in the delivery of a large-scale strategy and the reasons why such elements are significant for the social and economic success of a climate-related development. The exploration of a transformation model using the West Midlands National Park proposal (UK) demonstrates ways in which a broader vision allows the creation of a holistic approach across the whole region and how this has impacted decision making for the area. The third model focuses on re-integrating natural assets within a range of European cities while changing their operational systems, and it also demonstrates the significance of pan-European collaboration with the aim of achieving more sustainable cities. This paper demonstrates that all three models are based on the principles of design and the built environment; however they have facilitated different ways of planning that have led to effective decision making and sustainable strategies. By extracting key effective methodologies tested in these models, the paper demonstrates that successful environmental approaches

1. S. Nijhuis, S. and D. Jauslin, "Urban Landscape Infrastructures. Designing Operative Landscape Structures for the Built Environment," Research in Urbanism Series 3, no. 1 (2015): 1334.

2. Ibid. 
require a sequence of key actions such as vision, design quality, transformation, decision making and systemic change, and that these have so far been achieved through multidisciplinarity and collaboration.

\section{The Key Concepts}

Until recently the disciplines of landscape architecture, engineering, built environment and others have generally been treated as individual and separate disciplines, with little connection or interrelationship within strategic projects. Promoting the pioneer ideas of Shannon and Smets, and Belanger, Nijhuis and Jauslin argue that change is necessary: "infrastructures no longer belong to the realm of single disciplines [...], but to a crosscutting field that involves multiple disciplines in which the role of designers is essential."3 Infrastructure has gradually become accepted as something that applies to more than one discipline and there is increasing recognition that each profession has something to offer in this collaborative era. It is also pointed out that infrastructure developments do not only apply to technical issues but they require multiple actors and the active participation of design disciplines. ${ }^{4}$ However, there is still much more to do when it comes to climate resilience and the way in which infrastructure and the built environment can be part of a broader landscape approach that creates a sustainable vision for the whole city or region. Valdés et al. argue that "a resilient built environment is of paramount importance in achieving resilient cities," since the built environment is the glue between infrastructure, everyday life and human beings. Any disturbance to the built environment changes the social and economic characteristics, and it can therefore significantly affect human society. But what about destruction of the natural environment? We surely can admit, especially in a post-COVID-19 situation, that disturbances to the environment also significantly and adversely affect our health and wellbeing, ${ }^{6}$ communities, businesses and economies; and therefore it is imperative to understand and apply the concepts of sustainability and resilience. Two decades ago, Leal Filho stated that sustainability was becoming one of the most-used terms in environmental and scientific disciplines, but the evolution of this concept was a challenge. ${ }^{7}$ A decade later, there were indications that the concepts of low carbon and sustainability had been widely advocated, but the extent to which these ideas could be embedded in built

3. Ibid.

4. K. Shannon and M. Smets, The Landscape of Contemporary Infrastructure (NAi Uitgevers/ Publishers Stichting, 2010).

5. H. M. Valdés, D. Amaratunga and R. Haigh, "Making Cities Resilient: From Awareness to Implementation," International Journal of Disaster Resilience in the Built Environment 4, no. 1 (2013): 5-8.

6. F. Dutheil, J. S. Baker and V. Navel, “COVID-19 as a Factor Influencing Air Pollution?" Environmental Pollution 263, no. Pt A (2020): 114466.

7. W. Leal Filho, "Dealing with Misconceptions on the Concept of Sustainability," International Journal of Sustainability in Higher Education 1, no. 1 (2000): 9-19. 
environment and planning had not been easy to define. ${ }^{8}$ This paper recognizes that sustainability is a broad concept including economic elements and the futureproofing of cites, however in recent years this is used interchangeably with low/zero carbon and resilience.

Vale notes that "uneven resilience threatens the ability of cities as a whole to function economically, socially and politically." "The way in which our cities and regions are organized necessarily means that some parts are more resilient than others, and this reflects on underlying socio-economic disparities, topography and income amongst other factors. We could, therefore, argue that achieving a fully resilient city is a major and challenging task that requires a common framework between the different disciplines, and behavioural change in residents, professionals and politicians. It is based on this reasoning that Vale suggests that resilience is based on systemic strategies and the way these behave in different scales and social context. ${ }^{10}$

Valdés et al. argue that the concept of resilience is now widely adopted across academic and policy disciplines, and is often used in relation to disaster response ${ }^{11}$ but the methodology required to create a resilient city and how landscape design blends with infrastructure is only now beginning to be unpacked. As Vale suggests, there are multiple economic and social disparities within a city and, therefore, the goal for a whole city to become 'resilient' is almost always oversimplistic. ${ }^{12}$ The creation of the Sustainable Development Goals (SGDs) and their integration in the concept of resilience in cities and communities demonstrates the importance of tackling such issues from different angles, and that in order to strengthen resilience in our society, climatic extremes must be tackled in relation to economic and social challenges. ${ }^{13}$ Even though environmental challenges are experienced differently within an urban environment, there are signs that landscape design is able to create holistic visions ${ }^{14}$ for the current and future urban and rural infrastructure that can respond to these challenges and support better integrated environmental designs on a strategic. The collaboration of the built environment and landscape design disciplines does not eliminate the various disparities of a major city, but can build pathways that will allow these inequalities to be revealed, understood and addressed in the transition to a sustainable and resilient future.

Infrastructural Design and the Landscape as Environmental Assets

8. H. Yuan, P. Zhou and D. Zhou, "What is Low-Carbon Development? A Conceptual Analysis," Energy Procedia 5 (2011): 1706-1712.

9. L. J. Vale, "The Politics of Resilient Cities: Whose Resilience and Whose City?" Building Research \& Information 42, no. 2 (2014): 191-201.

10. Ibid.

11. Valdés, Amaratunga and Haigh, "Making Cities Resilient: From Awareness to Implementation," 2013.

12. Vale, "The Politics of Resilient Cities: Whose Resilience and Whose City?" 2014.

13. D. Acuti, M. Bellucci and G. Manetti, "Company Disclosures Concerning the Resilience of Cities from the Sustainable Development Goals (SDGs) Perspective," Cities 99 (2020): 102608.

14. D. Sijmons, Y. Feddes, E. Luiten, F. Feddes, M. Nolden and J. Bosch, Room for the River; Safe and Attractive Landscapes (The Netherlands: Blauwdruk, 2017). 
Infrastructure design has begun to be acknowledged in relation to urbanization, however the severe climatic phenomena (droughts, flash flooding, high temperatures) experienced in recent years are signs that the climate emergency will have serious adverse impacts on our cities and regions. The impacts of $1.5^{\circ} \mathrm{C}$ global warming, mentioned by the latest Intergovernmental Panel and Climate Change report, are likely to replace land use change as the major driver of ecosystem change in the coming years. ${ }^{15}$ Guerreiro et al. state that since over $75 \%$ of the population of the EU currently live in urban areas, as a result of the agglomeration of people, wider services and infrastructure, cities are particularly vulnerable to environmental phenomena. ${ }^{16}$ Examining the impact of the climate crisis at a global scale often puts an artificial distance between the phenomena themselves and their immediate effects on our cities, communities and economies. However, it is important to acknowledge that responding appropriately to the pressure put on our cities requires significant effort from everyone, and that local and national governments must develop and apply coherent adaptation as well as mitigation plans.

In evaluating what the built environment and landscape design disciplines can do to address some of these challenges we should recall Gossop's explanation that "the world's ability to absorb carbon is being steadily reduced through massive tree felling and other land use changes" 17 and consider how strategic plans can review and change our current practices. Over recent years local governments and national policy have begun to adapt to the climate challenges, and there are cases where policy reports urge actors "to maintain and improve the natural environment" 18 as Hardman et al. explain regarding the UK's National Planning Policy Framework (NPPF) and Natural Environment White Paper (NEWP). However, there is still no coherent process as to how infrastructural design can improve environmental challenges in cities and, furthermore, how our cities can become more resilient and sustainable future conurbations through built environment and design approaches.

Conceiving of infrastructure as landscape or vice versa is not new: from the second half of the eighteenth century infrastructure was regarded an integral part of the landscape by landscape designers."19 However, much remains to be discussed when it comes to ecology, sustainability and the urban environment.

15. Intergovernmental Panel on Climate Change (IPCC), Global Warming of $1.5^{\circ} \mathrm{C}$. Special Report on the Impacts of Global Warming of $1.5^{\circ} \mathrm{C}$ above Pre-Industrial Levels and Related Global Greenhouse Gas Emission Pathways, in the Context of Strengthening the Global Response to the Threat of Climate Change, Sustainable Development, and Efforts to Eradicate Poverty (eds.) V. Masson-Delmotte, P. Zhai, H.-O. Pörtner, D. Roberts, J. Skea, P. R. Shukla et al. 2018.

16. B. S. Guerreiro, J. R. Dawson, C. Kilsby, E. Lewis and A. Ford, "Future Heat-Waves, Droughts and Floods in 571 European Cities," Environmental Research Letters 13, no. 3 (2018): 034009.

17. C. Gossop, "Low Carbon Cities: An Introduction to the Special Issue," Cities 28 no. 6 (2011): 495-497.

18. M. Hardman, L. Chipungu, H. Magidimisha, P. J. Larkham, A. J. Scott and R. P. Armitage, "Guerrilla Gardening and Green Activism: Rethinking the Informal Urban Growing Movement," Landscape and Urban Planning 170 (2018): 6-14.

19. Nijhuis and Jauslin, "Urban landscape infrastructures. Designing operative landscape structures for the built environment," 2015. 
Cadenasso and Pickett state that even though progress had been maintained over the previous decade between the ideas of sustainable city design and urban ecology and that several frameworks had been developed, there was no "mature theory' on what urban ecology stands for, ${ }^{20}$ but perhaps key principles were beginning to emerge. Examining similar ideas and investigating the concept of urban resilience, Vale argues that it is the nature of the design and planning processes developed to make our communities energy efficient, environmentally sensitive, physically and socially attractive and adaptable to climate change, that will strengthen our cities and improve the quality of life for their residents. ${ }^{21}$ Even though this is not an easy form of resilience, it seems to be significant amongst the few options we have to address this global crisis. Jenks and Jones also agree that sustainability can be expressed in different forms and many of these have been systematically tested. $^{22}$ Although evidence as to how to develop sustainable urban forms remains rather inconclusive, it is clear that there is a growing interest and engagement in support of a more collaborative approach from the professionals (designers, landscape architects, planners) and the public.

It is now apparent that we have been ignoring nature with regards to the built environment, and that this has resulted in several challenges, of increasing severity, for our communities, economies and our wellbeing. As Nijhuis et al. remark "infrastructure over the last centuries was in service of the conquest of nature, whereby the environment was denied its natural dynamism in favour of more controlled and static systems." 23 Therefore, it is time to use the significance of the built environment and the visioning power of landscape architecture to establish that resilient cities need to support a broader sustainable vision while building with nature and not against it. Even though we are still exploring the best possible ways in which environmental frameworks can be applied to urban areas, there is no doubt that the lack of open space is likely to have negative impacts on biodiversity and ecosystem services for our cities and regions. ${ }^{24}$

\section{Methodology}

This paper explores innovative models that have identified principles and processes to support environmental development in conurbations. Focusing on the successful delivery of sustainable infrastructure developments, this paper has developed a theoretical framework based on key and necessary steps to achieve environmental stability and resilience in cities and regions. The models identify three major concepts that need to be addressed if we are to achieve resilient cities.

20. M. L. Cadenasso and S. T. Pickett, "Urban Principles for Ecological Landscape Design and Maintenance: Scientific Fundamentals," Cities and the Environment (CATE) 1, no. 2 (2008): 4.

21. Vale, "The Politics of Resilient Cities: Whose Resilience and Whose City?" 2014.

22. M. Jenks and C. Jones, Dimensions of the Sustainable City (Springer Science \& Business Media, 2009).

23. S. Nijhuis, D. Jauslin and C. De Vries, Flowscapes: Infrastructure as Landscape, Landscape as Infrastructure. Graduation Lab Landscape Architecture 2012/2013 (Delft: Delft University of Technology, 2012).

24. Jenks and Jones, Dimensions of the Sustainable City, 2009. 
The model of 'Design Quality and Implementation' indicates the importance of a holistic approach when it comes to landscape planning and environmental challenges. The 'Transformation' model demonstrates how perceptions are being changed using design methods to achieve a holistic vision and improve the landscape identity of a region. The third model -'Pan-European Systemic Change'links to a major part of strategic schemes; policy and systemic change, exploring new methodologies on how the latter can be achieved and influence policy and decision making.

These models have been identified through examination of three major landscape infrastructure schemes, the Room for the River programme (RftR), the National Park for the West Midlands (WMNP) proposal and the SATURN EIT Climate-KIC project. All schemes integrate the ideas of policy, environmental practice, decision making and landscape awareness; however, for the purposes of this paper, the strongest points of each project are extracted. The three schemes have demonstrated new methodological procedures in each of the key concepts and they have tested them either during real-life implementation or in further case studies. Therefore such schemes are considered innovative in the ways in which they have dealt with current challenges and have given indications of how systemic change can be achieved. The first scheme, 'RftR-Design Quality and Implementation', is a completed landscape-led programme that demonstrates several methodological as well as policy delivery practices when implementing a climate adaptation scheme, and it is selected to represent the successful integration of design quality into the built environment. The WNMP-'Transformation' as well as the SATURN-'Pan-European Systemic Change' models are ongoing at the time of writing and therefore this paper will report on the current findings about the way in which landscape design can form perceptions and support policy in cities and regions. The methodology behind the three presented strategic schemes includes an in-depth analysis of their structure, project framework and design as well as policy methodological steps by the lead researcher conducted at the various locations of the schemes and included field visits, observations, interviews with experts and workshop activities with local stakeholders.

The data collected for this paper is based on visuals, stakeholder activities and observations. Maps, policy and technical documents, visual material, case study notes, drawings and images of sustainable approaches as well as outputs from the different workshops with professionals and stakeholders were collected and subjected to content analysis.

\section{The Design Quality and Implementation Model - The Room for the River}

Through a climate adaptation programme this model demonstrates the significance of landscape design, low carbon and spatial quality as ways to deliver environmentally-based infrastructure on a strategic scale. The RftR is a nationalscale climate adaptation programme that was intended to form sustainable ways of dealing with rising sea levels in the country. Based on a newly developed design strategy, the programme ensured a high level of protection against rising water 
levels in 34 project locations across the Netherlands while introducing design quality and landscape awareness as a major part of the environmental aspect of the scheme. The scheme is a good example of how quality of space and climate adaptation principles are embedded from the conceptual to the implementation stage of a strategic scheme. Using a policy and communication framework especially developed for this programme, RftR has also managed to educate professionals and the public about the impact of climate crisis through landscape design and the ways in which the 34 projects have been delivered.

The successful establishment of this major infrastructure scheme included two key goals: water safety and spatial quality. By putting the environmental and design ideas at the core of the whole scheme, the RftR offers an innovative alternative to traditional planning and the way in which the built environment has previously been conceived. It is important to mention that, based on evidence collected by the authors, the support received by the Dutch government and the continuous involvement of the local and national authorities during the various stages of the scheme have been proven essential with regards to the delivery of environmental and landscape quality ideas. ${ }^{25}$

To unpack and fully understand the impact of this model in relation to design quality and delivery, Figures 1-3 demonstrate key conceptual diagrams, a diagrammatic masterplan and one detailed visualization of the Nijmegen city project, one of the programme's 34 locations.

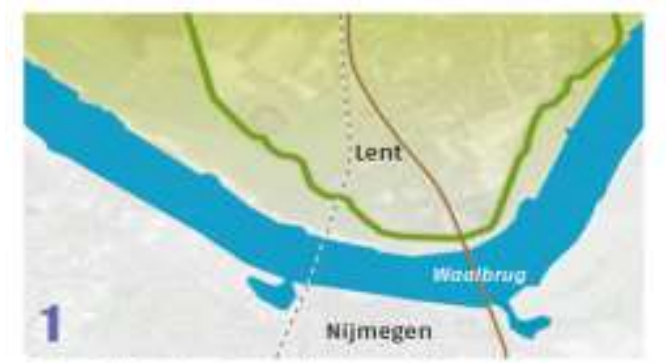

The initial situation with the existing dike.

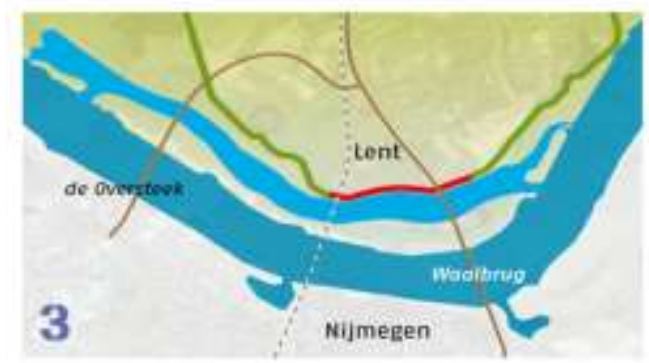

An ancillary channel is to be dug in order to give the river more room. This will create an elongated island.

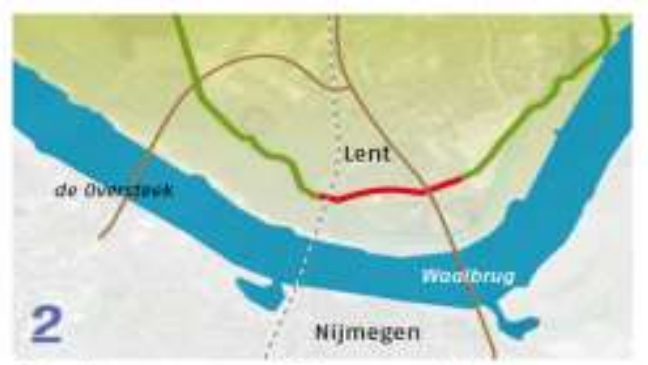

The dike was moved 350 metres inland.

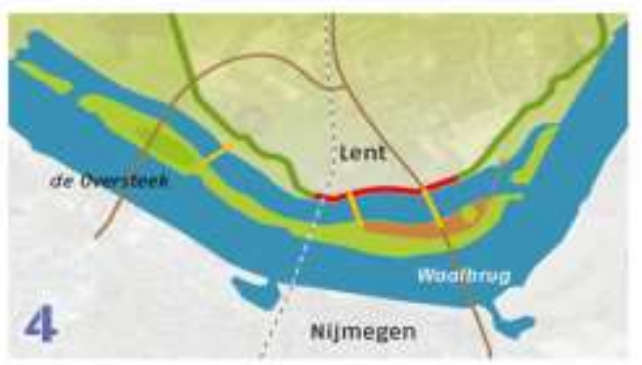

Bridges across the ancillary channel.

Figure 1. Dyke Relocation and New River Waterflow Diagram for the City of Nijmegen, Room for the River Programme

Source: Image Courtesy: Rijkswaterstaat, Room for the River.

25. A. Nikologianni, K. Moore and P. J. Larkham, "Making Sustainable Regional Design Strategies Successful," Sustainability 11, no. 4 (2019): 1024. 
The significance of this scheme is in the central position of the policy and governmental support, and the continuous communication between multidisciplinary teams and national/local authorities. The success of its methodology in delivering spatial quality and hydrological efficiency at such a scale, is a result of the integration of landscape design with the built environment. This unique project has managed to provide an environmental vision on a strategic scale (Figure 1), whilst simultaneously fully supporting the businesses and economy of the area by creating a destination for residents and visitors (Figure 2). The true impact of how quality of space can be implemented is shown in Figure 3, where, through the medium of a pedestrian and cycling bridge, the concept of climate crisis and awareness is being vividly highlighted. Using the physical barrier between one's body and water, this design forces one's mind to understand what rising water level would mean and how an urban environment could adapt to it. Landscape architecture creates new ways of experiencing nature and enhances learning and environmental awareness at the point when quality of space is successfully implemented in a city. Landscape design and infrastructure must act as enablers to ensure a better understanding of nature and how to create sustainable urban environments.

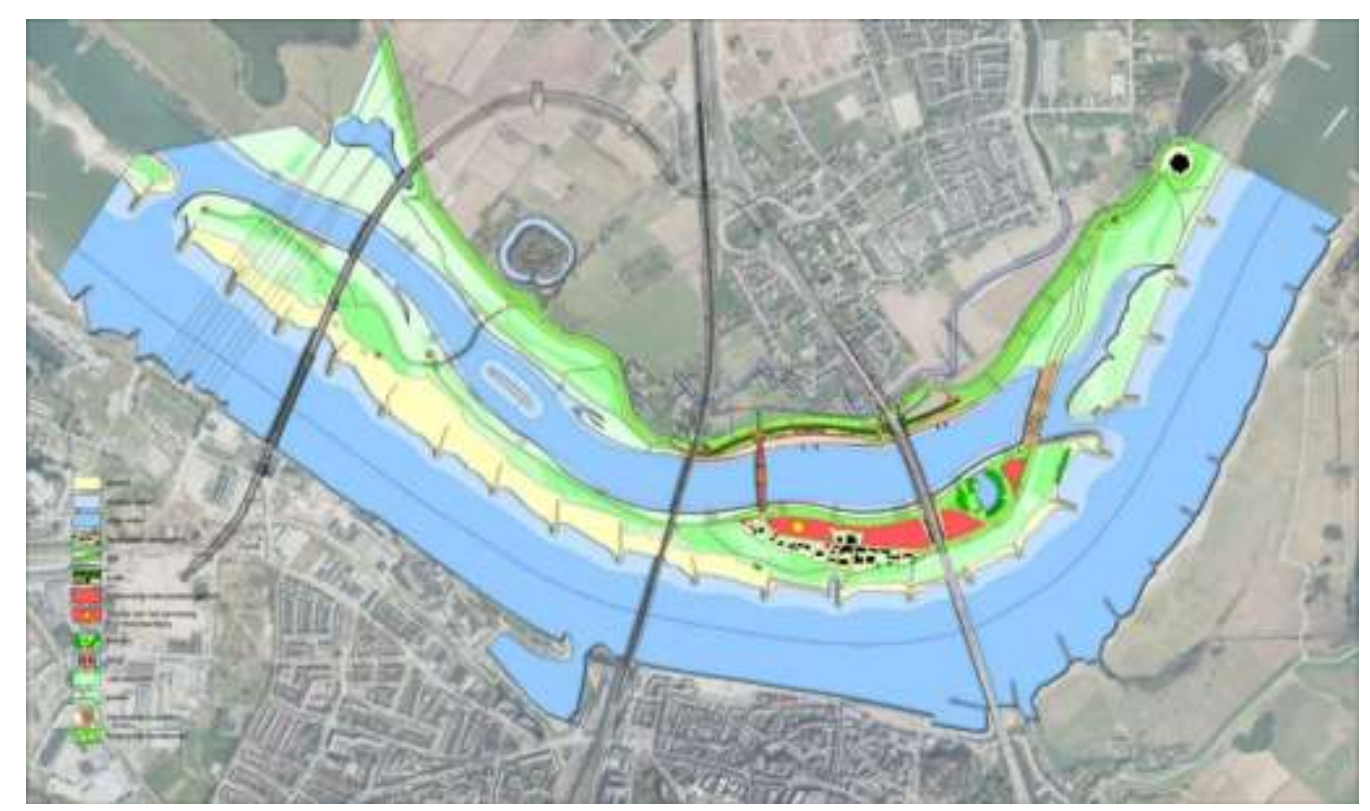

Figure 2. Nijmegen Masterplan for the Room for the River Programme

Source: Image Courtesy: Rijkswaterstaat, Room for the River.

Looking beyond the initial design and the necessary engineering work for such a major infrastructure development, these visualizations demonstrate design expertise and the full integration of environmental and landscape ideas. The diagrams enable us to unpack the initial conceptual ideas of hydrological efficiency and spatial quality, and to understand how such an area can be designed with suitable environmental principles without losing either quality or cultural and social engagement. Since the Nijmegen RftR project is completed and operational, it is appropriate to identify the design of the Citadel Bridge (Figure 3) as a good 
example of how the broad vision and concept can be interpreted in reality and work as an exemplar of real-life environmental awareness and education through our daily interactions or routes within a city. Although a significant carbon footprint has been incurred in the scheme's delivery, its design and implementation have been justified as being beneficial for future-proofing the region and its completion will enhance the environmental, economic and social benefits for decades.

The delivery and successful continuation of the RftR strategic programme is a current example of how a landscape-led and environmental vision can be implemented without losing the key elements that make it unique and innovative, such as quality of space and climate adaptation methods. The Nijmegen RftR project is only one element of the RftR, but one which has dealt successfully with the transformation of an urban environment to an environmentally-friendly destination without compromising safety or quality of space. Its delivery has not been easy, but its success has resulted from a continuous communication process between governmental and local authorities, policy and infrastructure, with the important characteristic that it had landscape designers in a leading role of this development that preserved a clear climate adaptation concept.

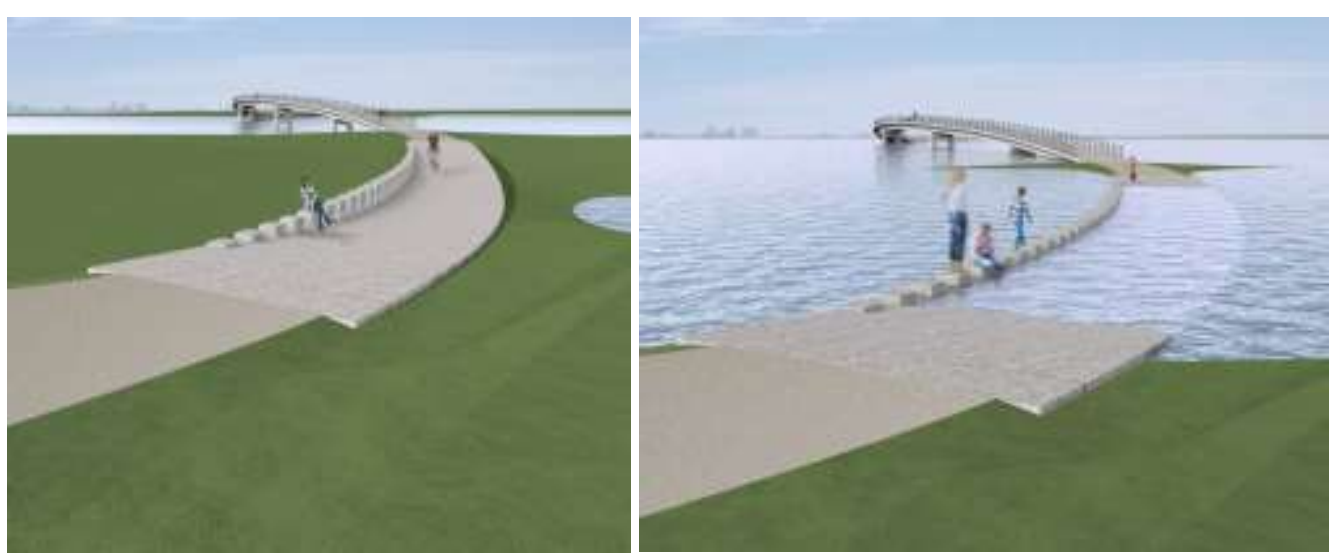

Figure 3. Citadel Bridge Designed by NEXT Architects Connecting the City of Nijmegen with the Veur-Lent Island. Left: Normal Situation; Right, Flood-Resistant Design

Source: Image Courtesy: Rijkswaterstaat, Room for the River.

\section{The Transformation Model - The West Midlands National Park (WMNP)}

The second model explores the major transformation opportunities that a landscape-led infrastructure development can bring to a region. The West Midlands National Park (WMNP) proposal developed by the Critical Artistic Thinking in Design (CATiD) research centre at Birmingham City University offers a unique approach for the area identifying resilient ways to re-discover a hidden landscape 
when supporting the social, historic and economic characteristics of the region. ${ }^{26}$ The significance of this model is derived from several powerful drawings and a stakeholder engagement process that has allowed policy and governmental authorities to redefine the way in which they deal with regional scale, to the point that in June 2020 the WMNP was formally adopted by the West Midlands Combined Authority (WMCA) as the vehicle for a green recovery in the region in a post-COVID-19 era. $^{27}$

The WMNP proposal offers a way to see a region differently, through the lens of landscape and climate crisis, that allows evaluation of the current decisionmaking methods and aims to lead to further transformation of the region towards a carbon-neutral future. By proposing a close relationship between people and place, and building on strategic initiatives, this model envisions the creation of an iconic landscape that will enhance identity of place. Its core principle is not to examine the concepts of land, sustainability, economy and culture as individual elements of a region, but to demonstrate that a successful transformation of a region needs to recognise these issues are interrelated and to produce a vision that will address them all to the best possible scenario. With the use of powerful diagrammatic but carefully-developed drawings, the WMNP aims to reveal the significance of visual material to the way in which we understand and act upon the landscape. The visual material developed by the WMNP is intentionally abstract (Figure 4) and focuses on the whole region instead of specific areas. In contrast to what has been presented for the RtfR project, where detailed drawings where used as examples, the WMNP is taking us one step back to build and establish a vision for the whole region, before we move on to more detailed and specific drawings. The RtfR project had also followed such a process in moving from the broader to the local scale. Through visioning workshops and stakeholder activities, this proposal has begun to demonstrate alternative ways to change the perceptions of the area and allow local authorities and communities to imagine a different, much more positive, future, particularly in some of the most challenging parts of the region.

Part of the WMNP process is to use design to redefine the region. Working with large-scale maps, as shown in Figure 4, the project unpacks some of the most important physical and cultural characteristics of an area (water, history, environment, society) generating a visual method that helps public and private actors to realise the potential of the region without being challenged by current hurdles such as business development, economy, housing problems and pastshaped perceptions. Even though the project is still in its conceptual phase, it has already begun to change perceptions in the region (WMNP to lead the region's green recovery - June 2020), enabling multidisciplinary collaboration and impacting on local and national decision making and the way in which policy is formed for our cities relating to nature. Challenging all stakeholders to think and

26. K. Moore, "Towards New Research Methodologies in Design," in The Routledge Research Companion to Landscape Architecture, 312-323 (eds.) E. Braae and H. Steiner. Routledge, 2018.

27. Birmingham City University (BCU), The West Midlands National Park to Lead the Region's Green Recovery (Birmingham, UK: Birmingham City University, 2020). 
act differently (with the landscape as the starting point) and using design as a method to build a spatial vision, the WMNP has now started to overcome the expected initial denial and to be embraced by regional and national institutions and authorities.

Exploring post-COVID-19 scenarios and the way in which this pandemic has forced us to rethink and re-evaluate our response to nature in a city context, the transformation model introduced by the WMNP is an innovative approach that can be beneficial for different regions at a global scale. The accessibility and proximity of open spaces, especially if living in a densely-built-up urban environment, together with the advice to reduce long-distance travelling, has encouraged communities to get to know their neighbourhoods better in an unprecedented way. Since February/March 2020 it has been more apparent than ever that nature and green spaces play a major role in the way in which people can cope with stress and support their mental and physical health. The lockdown measures adopted as a response to the COVID-19 crisis have increased some types of outdoor recreational activity but have also demonstrated the "importance of access to green open spaces that are interwoven within the built-up matrix." ${ }^{28}$ Therefore, it is clear that the built environment and landscape design have a major role to play in futureproofing our cities both in a climate crisis and with a public health perspective. As Venter et al. mention, "the current pandemic reveals some important dilemmas we might face regarding green justice on the path towards urban planning for future sustainable cities" 29 and the transformation model introduced in this section responds to the needed environmental as well as social and economic transition of the area. If we have learned something from this recent crisis is that no matter how deep in an urban environment we live, this cannot be wholly detached from nature and the landscape. Therefore, if we are to achieve resilience, it is time to reexamine our current processes and, for that to be successful, we need to constantly challenge ourselves as well as the system to change obsolete practices and perceptions.

28. Z. Venter, D. Barton, H. Figari and M. Nowell, Urban Nature in a Time of Crisis: Recreational Use of Green Space Increases during the COVID-19 Outbreak in Oslo, Norway (Oslo, Norway: Norwegian Institute for Nature Research, 2020).

29. Ibid. 


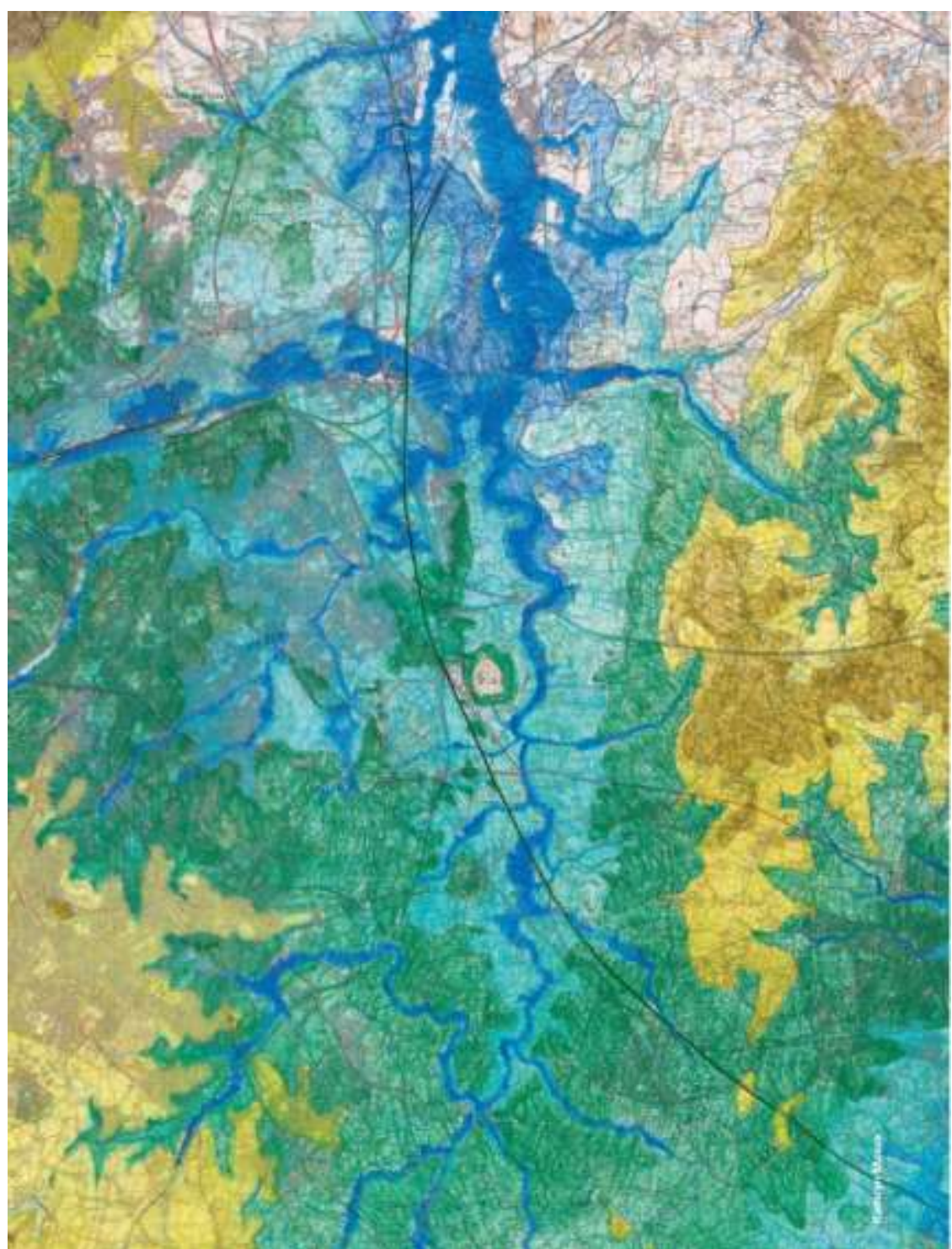

Figure 4. West Midlands Valleys Diagram Emphasizing the Topography and Hydrology of the Area, Made for the WMNP Proposal Source: Image by Kathryn Moore.

\section{Natural Assets and the Engagement of Cities - The SATURN Pan-European Model}

SATURN is an EIT Climate-KIC pan-European project which deals with the re-integration of natural assets and aims to support cities and regions transition to a carbon neutral future. ${ }^{30}$ Its aspiration is to extract best approaches from across

30. A. Nikologianni, A. Betta, A. Pianegonda, S. Favargiotti, K. Moore, N. Grayson et al. "New Integrated Approaches to Climate Emergency Landscape Strategies: The Case of PanEuropean SATURN Project,” Sustainability 12, no. 20 (2020): 8419. 
Europe, create a supportive visioning and stakeholder process for local and regional authorities and test how such methods bring systemic change. With its focus on governance and an established collaboration between Birmingham (UK), Trento (Italy) and Gothenburg (Sweden), the project examines how landscape design and the built environment can support the movement towards urban resilience and what processes are required to do so across Europe. Although SATURN is an ongoing project, and therefore this paper only presents data from its first year of activity, it has already attracted international interest in response to its innovative communication process between the multidisciplinary teams and its goal to create a framework on valuing the landscape through design/visioning and a stakeholder engagement process using visual tools and drawings.

The project focuses on the relationship between cities, the landscape identity, natural assets in each area and food growing methods as well as social characteristics. At the core of this model is the principle that landscape visioning and resilient city planning is not an easy 'copy-paste' or 'one size fits all' activity, but through the development of a regional vision, strong communication and collaborative working, it is possible to develop methods, principles and frameworks applicable in other European and international countries. The process established by this model aims to generate holistic strategic frameworks, advise cities on landscape management, development and transformation, engage urban populations and help them understand the significance of their landscape and the impact of local food production. A crucial part of this initiative is also the re-evaluation of policy and strategic documents for the cities and the institutions involved, exploring ways to identify alternative methods to support the transition to sustainable communities.

Based on a three-tiered approach, the SATURN analysis includes a) an exploration of a holistic spatial approach and framework for each region, b) the use of ecosystem services and natural capital to map and evaluate the landscape potential of an area and c) the creation of a systems approach as a way to reveal new capacity building, stakeholder engagement processes and other hidden actors between the participating cities. A series of visioning and stakeholder activities have been designed and are now being tested throughout the consortium as well case studies being investigated. The visioning activities focus on how a holistic approach can be established starting with the views of each participant and progressing with a visual exercise by the different teams (Figure 5). The stakeholder, mapping, analysis and engagement exercises follow a series of visual tools that deal with the engagement process of different project actors (Figure 6). Using the built environment as well as design methods to demonstrate the value of the land, the SATURN model aims to build a comprehensive and flexible framework to guide cities on a more resilient path and spread awareness of what such an environment might be like. The goal is not only to highlight the natural assets of each area, but to build a collaborative network that will improve and update the knowledge, policy documents and engagement strategies and co-create an economically sustainable, scalable and environmentally friendly process for cities and regions. Specific tools are also being developed to support decision making at local and regional levels. 


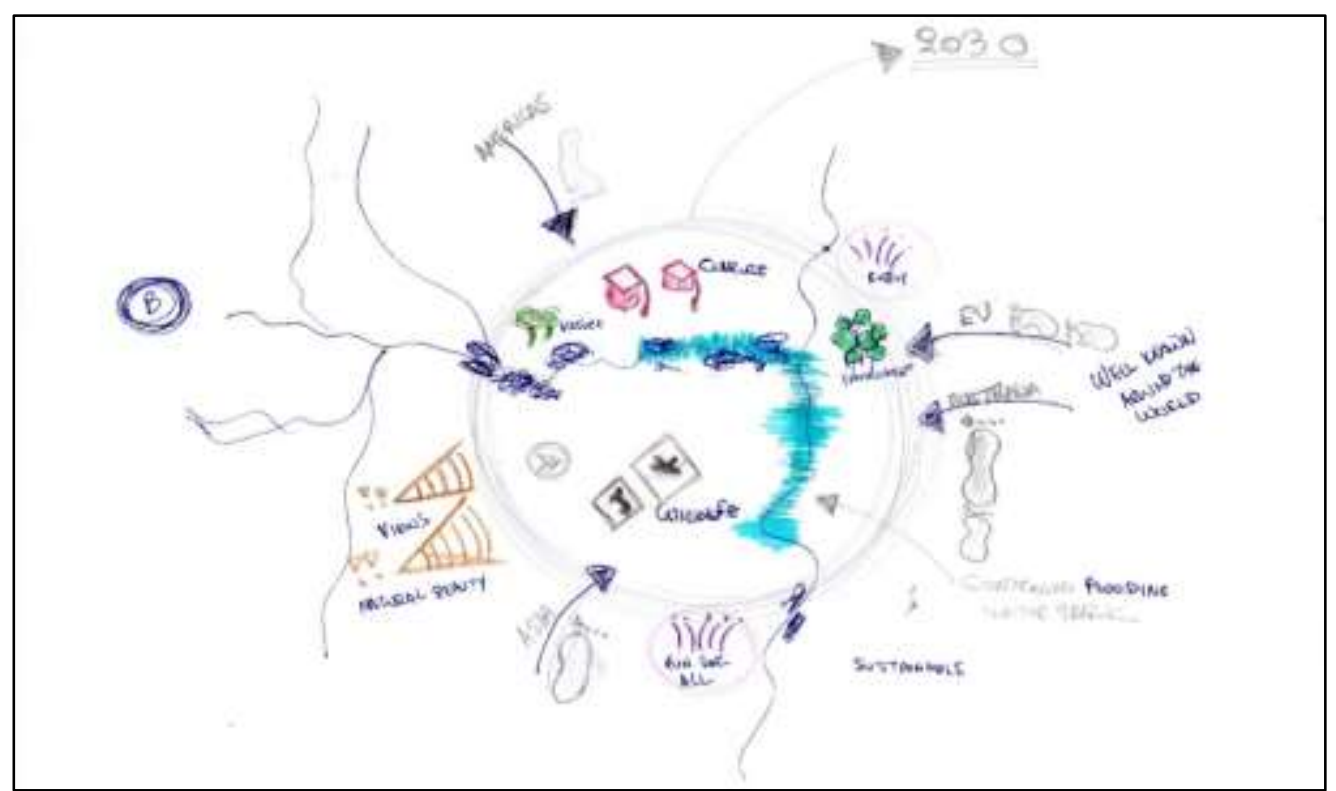

Figure 5. Tame Valley (West Midlands, UK) Vision Developed during the Visioning Exercise Series within SATURN Programme

Source: Image: Anastasia Nikologianni.

As this paper investigates how landscape design and the built environment can be the vehicles to promote and contribute to resilient cities, the issue of governance, nature and landscapes examined by SATURN are considered very significant. This pan-European model aims to change the land management approach which is currently determined by ownership and silos, and consider the natural assets of each area with a fresh approach aiming to attract business, tourism, and entrepreneurial activities while providing for the environment and the community. The existing fragmentation around the landscape, its governance and people's engagement are believed to be leading to a singular, often only technologically-focused, approach on climate change. The environmental approach of SATURN, with respect to the built environment, is not based on preservation or totally new designs, but on a restoration of the landscape value and the natural environment as ideas in order to increase the pride, the interest and awareness for our cities. Local authorities are often the first level of interaction with the public and they (local authorities) often have very different needs or aspirations, even within the same region. Especially in a post-COVID-19 era, it is expected that "substantial changes to future design, use, and perceptions of public space" 31 are unavoidable, and this paper argues that SATURN is already working towards this direction in relation to the climate crisis and the landscape in urban and regional areas.

31. Venter, Barton, Figari and Nowell, Urban Nature in a Time of Crisis: Recreational Use of Green Space Increases during the COVID-19 Outbreak in Oslo, Norway, 2020. 


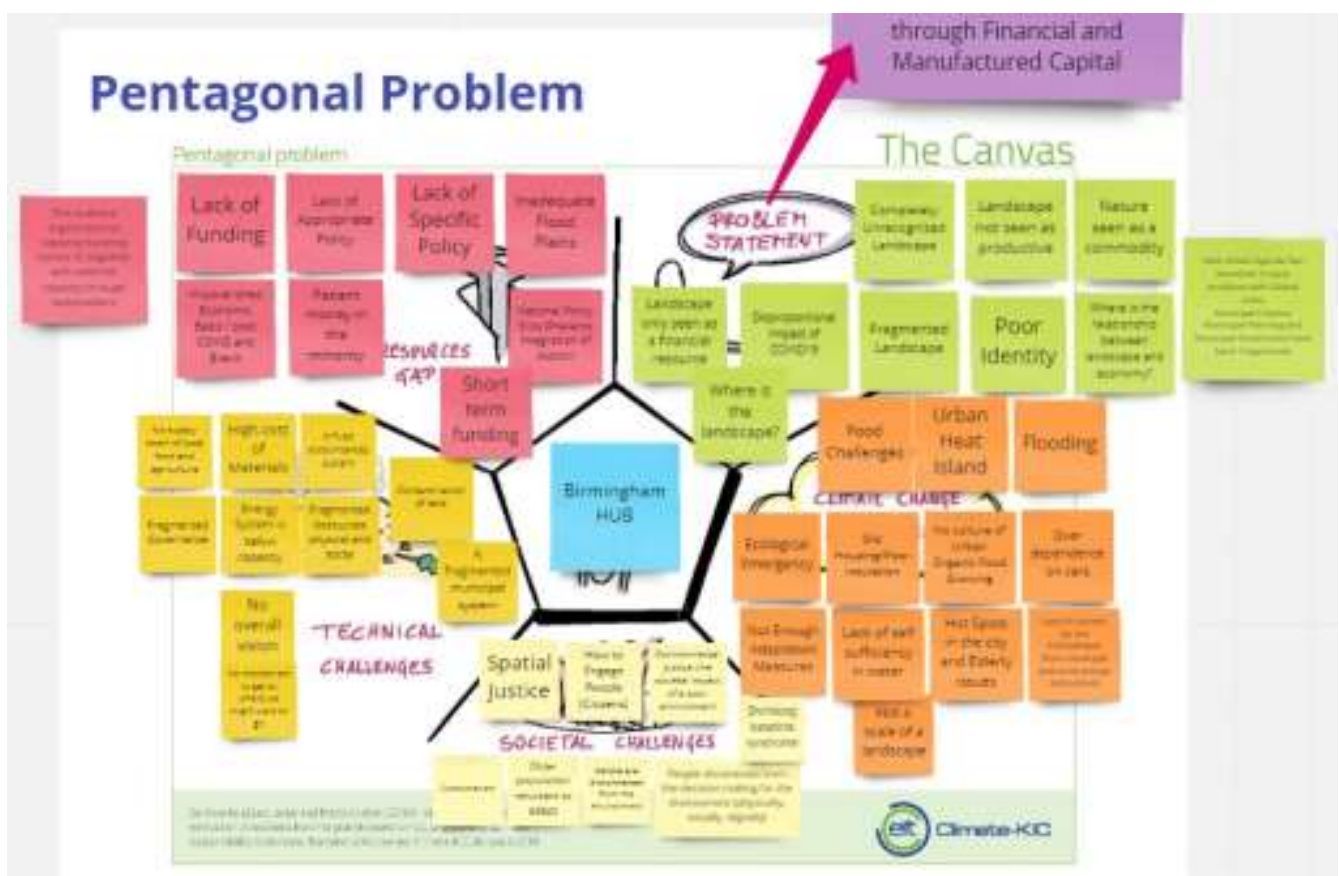

Figure 6. The Pentagonal Problem Activity is One of the First Steps of a Series of Activities for Stakeholder Mapping and Engagement. This Activity Uses a Visual Tool from EIT Climate-KIC's Visual Toolbox

Source: Example Presented from Birmingham Hub.

\section{Discussion}

The three-model approach presented above demonstrates significant ways in which innovative design and planning can address climate extremes and play a major role in a sustainable transition of our cities. A transformative vision, a wellthought project framework, the integration (in the design concept and framework) of qualities such as environmental characteristics and quality of space are key steps that lead to successful delivery of sustainable cities. Systemic change in civic and regional processes, alternative decision-making methods and the support of policy are essential in order to achieve integration of climate-related characteristics and spatial quality elements in strategic design. The successful integration of design quality during the implementation phase of an environmentally focused scheme, such as the Nijmegen RftR project, provides justification that a strategic development should not only rely on an effective engineering approach, but a comprehensive plan that includes public engagement and education. The model developed in the RftR has put design at the core of the project framework and has used it as a tool to deliver a climate-efficient scheme that addresses water safety without compromising the spatial quality, economic or cultural elements of the area. The coherent design concept has been assessed by multidisciplinary teams and discussed with multiple stakeholders before it reaches delivery point, however key principles (e.g., spatial quality and hydrological efficiency) were able to be delivered through their integration in a binding policy framework for the scheme. 
The impact that the built environment and landscape design have in the delivery of resilient cities depends on professional expertise, the ability to exchange ideas and the need to establish a strong vision in alignment with the environmental challenges and the political situation of the area.

While embedding climate and spatial qualities is of major importance in large-scale infrastructural developments, the transition to urban resilience is still subject to other factors, as is demonstrated by the WMNP project. Both an indepth understanding of an area, and a willingness to diverge from the well-known methods and processes adopted for decades by public and private stakeholders, is a crucial step in the path towards sustainable cities. Decision making in the past has often been driven by specific agendas, without necessarily following the environmental or even the cultural and social needs of a city. This paper argues that landscape design can unpack this neglected information, leading to new knowledge to support environmental, economic and social transformation. The WMNP has demonstrated that drawings and visual materials are powerful tools to build visions of a region as well as to reveal 'hidden' natural and social characteristics that are either neglected or overlooked in development and policy, but may be part of everyday local life. Based on a visioning method that allows for the establishment of a bigger picture instead of just practical challenges (e.g., where to build, transport), this process gives flexibility to the designers to examine an area with the lens of landscape design and to the public the chance to discover more about their region as a whole.

The engagement with local governance embedded in the SATURN project is another significant element contributing to the sustainable framework. Even if environmental characteristics, spatial quality elements and a new decision-making process are in place, the opportunity to collaborate with local authorities and cocreate tools with public and private stakeholders is crucial in order to attract the interest of other cities and regions at a global level. The scope of SATURN, which is to provide solutions for the challenge of fragmented governance and neglected landscape while involving its major actors (city, public, major institutions, environmental organizations, agriculture sector and entrepreneurs), is a perfect mechanism to create a positive climate for this transition. SATURN engages with cities at a fundamental level and, through a series of capacity building and stakeholder engagement sessions, is seeking to bring systemic change. The three Hubs (Birmingham, Trento, Gothenburg) working on SATURN test the outcomes of a systemic change and the impact this will have to the decision making and overall transition of the city to a carbon neutral community.

\section{Conclusions}

The environmental challenges we face, the increase of extreme climate phenomena and the need for sustainable cities are increasingly evident. The novel experience of living during a global pandemic has emphasized the significance of, and need for, natural environments in order to support our physical and mental health and, therefore, the provision of and access to open spaces in urban or 
densely-populated areas is becoming non-negotiable. An environmental or sustainable approach in design, infrastructure and any kind of development is a one-way route in the response to the climate crisis and this can be achieved through collaborative, multidisciplinarity and pioneer concepts that embed environmental as well as cultural and economic benefits for our cities.

The steps revealed by the three models, in addition to the assets of policy, strategic documents, and multidisciplinary teams which were adopted by all of the examples, demonstrate that achieving the goal of resilient cities is not an easy exercise, but it is achievable. The examination of those three strategic schemes has led to the conclusion that a major systemic change is needed in order to fully achieve environmental outcomes in spatial design and infrastructure. As a result of the large scale at which these schemes operate, it is not possible to generate environmental effects by addressing only one of the major aspects (climate, economy, society) or by considering them as engineering or technological innovations (smart cities, mobility). The three-model approach demonstrates that design, vision, multidisciplinarity and close communication must be the tools across the whole process of a scheme from concept to delivery. The close links to policy and legislation are necessary to ensure that the core visions and quality are not overlooked during implementation.

Recommendations by this paper include: open mindedness in the design and implementation process. Landscape design is suggested to be the medium that brings all environmental, engineering, economic and cultural characteristics together, however this cannot be achieved if there are no multidisciplinary teams within a strategic scheme. A systemic change is not easy, but the creation of a vision (in a diagrammatic way/drawing) for the city/region of interest will support this process and will provide further input as well as new tools to decision makers. Key elements of the vision and concept (e.g., climate resilient, spatial quality) should be embedded in the project framework and addressed as main goals in delivery while at the same time their delivery is 'protected' by policy or legislation. These principles apply to different project frameworks; however, it is important to have a dedicated team that will link and ensure such issues are addressed in relation to the specific area, its needs and characteristics.

Determination, strong leadership, willingness to identify new ways of thinking and cross-silo collaboration are key steps in the way to achieve sustainable cities. The power of landscape design to reveal the value of land, our memories and sense of belonging has been identified as a significant factor in changing perceptions and creating visions. The major role played by the built environment in global policy, if used effectively, will encourage design and planning that will make our communities increasingly environmentally and energy efficient, without sacrificing their natural assets by adopting only mass-produced technological tools that promise 'resilience in a box'. 


\section{Bibliography}

Acuti, D., M. Bellucci and G. Manetti. "Company Disclosures Concerning the Resilience of Cities from the Sustainable Development Goals (SDGs) Perspective." Cities 99 (2020): 102608.

Birmingham City University (BCU). The West Midlands National Park to Lead the Region's Green Recovery. Birmingham, UK: Birmingham City University, 2020.

Cadenasso, M. L. and S. T. Pickett. "Urban Principles for Ecological Landscape Design and Maintenance: Scientific Fundamentals." Cities and the Environment (CATE) 1, no. 2 (2008): 4.

Dutheil, F., J. S. Baker and V. Navel. "COVID-19 as a Factor Influencing Air Pollution?" Environmental Pollution 263, no. Pt A (2020): 114466.

Gossop, C. "Low Carbon Cities: An Introduction to the Special Issue." Cities 28 no. 6 (2011): 495-497.

Guerreiro, B. S., J. R. Dawson, C. Kilsby, E. Lewis and A. Ford. "Future Heat-Waves, Droughts and Floods in 571 European Cities." Environmental Research Letters 13, no. 3 (2018): 034009.

Hardman, M., L. Chipungu, H. Magidimisha, P. J. Larkham, A. J. Scott and R. P. Armitage. "Guerrilla Gardening and Green Activism: Rethinking the Informal Urban Growing Movement." Landscape and Urban Planning 170 (2018): 6-14.

Intergovernmental Panel on Climate Change (IPCC). Global Warming of 1.5oC. Special Report on the Impacts of Global Warming of $1.5^{\circ} \mathrm{C}$ above Pre-Industrial Levels and Related Global Greenhouse Gas Emission Pathways, in the Context of Strengthening the Global Response to the Threat of Climate Change, Sustainable Development, and Efforts to Eradicate Poverty. Edited by V. Masson-Delmotte, P. Zhai, H.-O. Pörtner, D. Roberts, J. Skea, P. R. Shukla et al. 2018.

Jenks, M. and C. Jones. Dimensions of the Sustainable City. Springer Science \& Business Media, 2009.

Leal Filho, W. "Dealing with Misconceptions on the Concept of Sustainability." International Journal of Sustainability in Higher Education 1, no. 1 (2000): 9-19.

Moore, K. "Towards New Research Methodologies in Design." In The Routledge Research Companion to Landscape Architecture, 312-323. Edited by E. Braae and H. Steiner. Routledge, 2018.

Nijhuis, S. and D. Jauslin. "Urban Landscape Infrastructures. Designing Operative Landscape Structures for the Built Environment." Research in Urbanism Series 3, no. 1 (2015): 13-34.

Nijhuis, S., D. Jauslin and C. De Vries. Flowscapes: Infrastructure as Landscape, Landscape as Infrastructure. Graduation Lab Landscape Architecture 2012/2013. Delft: Delft University of Technology, 2012.

Nikologianni, A., K. Moore and P. J. Larkham. "Making Sustainable Regional Design Strategies Successful." Sustainability 11, no. 4 (2019): 1024.

Nikologianni, A., A. Betta, A. Pianegonda, S. Favargiotti, K. Moore, N. Grayson et al. "New Integrated Approaches to Climate Emergency Landscape Strategies: The Case of Pan-European SATURN Project." Sustainability 12, no. 20 (2020): 8419.

Shannon, K. and M. Smets. The Landscape of Contemporary Infrastructure. NAi Uitgevers/Publishers Stichting, 2010.

Sijmons, D., Y. Feddes, E. Luiten, F. Feddes, M. Nolden and J. Bosch. Room for the River; Safe and Attractive Landscapes. The Netherlands: Blauwdruk, 2017. 
Valdés, H. M., D. Amaratunga and R. Haigh. "Making Cities Resilient: From Awareness to Implementation." International Journal of Disaster Resilience in the Built Environment 4, no. 1 (2013): 5-8.

Vale, L. J. "The Politics of Resilient Cities: Whose Resilience and Whose City?" Building Research \& Information 42, no. 2 (2014): 191-201.

Venter, Z., D. Barton, H. Figari and M. Nowell. Urban Nature in a Time of Crisis: Recreational Use of Green Space Increases during the COVID-19 Outbreak in Oslo, Norway. Oslo, Norway: Norwegian Institute for Nature Research, 2020.

Yuan, H., P. Zhou and D. Zhou. "What is Low-Carbon Development? A Conceptual Analysis." Energy Procedia 5 (2011): 1706-1712. 